\title{
Corrigendum
}

\section{A comparison of heart rate variability, n-3 PUFA status and lipid mediator profile in age- and BMI-matched middle-aged vegans and omnivores - CORRIGENDUM}

Ana M. Pinto, Thomas A. B. Sanders, Alexandra C. Kendall, Anna Nicolaou, Robert Gray, Haya Al-Khatib and Wendy L. Hall

(First published online 3 April 2017)

doi: https://doi.org/10.1017/S0007114517000629

In the version of this article initially published, there was an error in the definition of one of the parameters of heart rate variability. Specifically, in the list of abbreviations pNN50 is defined as "the percentage of adjacent NN intervals that differ by $>50 \%$ ". This needs to be corrected to "the percentage of adjacent NN intervals that differed by $>50 \mathrm{~ms}$ ". The same error occurs in the text at the bottom of the first column on page 671 and in the footnote of Table 4 on page 681. 